\title{
Plasma L-arginine levels distinguish pulmonary arterial hypertension from left ventricular systolic dysfunction
}

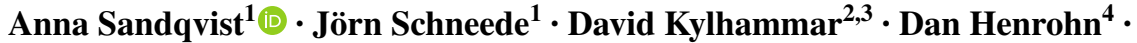 \\ Jakob Lundgren ${ }^{2,3} \cdot$ Mikael Hedeland $^{5,6}$ • Ulf Bondesson ${ }^{5,6}$ • Göran Rådegran ${ }^{2,3}$ • \\ Gerhard Wikström ${ }^{4}$
}

Received: 8 May 2017 / Accepted: 22 September 2017 / Published online: 3 October 2017

(c) The Author(s) 2017. This article is an open access publication

\begin{abstract}
Pulmonary arterial hypertension (PAH) is a life-threatening condition, characterized by an imbalance of vasoactive substances and remodeling of pulmonary vasculature. Nitric oxide, formed from L-arginine, is essential for homeostasis and smooth muscle cell relaxation in PAH. Our aim was to compare plasma concentrations of L-arginine, asymmetric dimethylarginine (ADMA), and symmetric dimethylarginine (SDMA) in PAH compared to left ventricular systolic dysfunction (LVSD) and healthy subjects. This was an observational, multicenter study comparing 21 patients with PAH to 14 patients with LVSD and 27 healthy subjects. Physical examinations were obtained and blood samples were collected. Plasma levels of ADMA, SDMA, L-arginine, L-ornithine, and L-citrulline were analyzed using liquid chromatography-tandem mass spectrometry (LC-MS/MS). Plasma levels of ADMA and SDMA were higher, whereas L-arginine and L-arginine/ADMA ratio were lower in PAH patients compared to healthy subjects
\end{abstract}

Anna Sandqvist

anna.sandqvist@umu.se

1 Department of Pharmacology and Clinical Neuroscience, Clinical Pharmacology, Umeå University, 90187 Umeå, Sweden

2 Department of Clinical Sciences Lund, Cardiology, Lund University, Lund, Sweden

3 The Section for Heart Failure and Valvular Disease, Skåne University Hospital, Lund, Sweden

4 Department of Medical Sciences, Cardiology, Uppsala University, Uppsala, Sweden

5 Department of Chemistry, National Veterinary Institute (SVA), Uppsala, Sweden

6 Department of Medicinal Chemistry, Analytical Pharmaceutical Chemistry, Uppsala University, Uppsala, Sweden $(p<0.001)$. Patients with PAH also had lower levels of L-arginine than patients with LVSD $(p<0.05)$. L-Arginine correlated to 6 min walking distance $(6 \mathrm{MWD})\left(r_{\mathrm{s}}=0.58\right.$, $p=0.006)$ and L-arginine/ADMA correlated to WHO functional class $\left(r_{\mathrm{s}}=-0.46, p=0.043\right)$ in PAH. In conclusion, L-arginine levels were significantly lower in treatment naïve PAH patients compared to patients with LVSD. Furthermore, L-arginine correlated with 6MWD in PAH. L-arginine may provide useful information in differentiating PAH from LVSD.

Keywords Pulmonary arterial hypertension $\cdot$ Left heart failure - Systolic dysfunction · L-Arginine · Dimethylarginines

\section{Introduction}

Pulmonary arterial hypertension (PAH) is a rare disease characterized by endothelial dysfunction and pulmonary vascular remodeling, leading to elevated pulmonary vascular resistance, right ventricular heart failure, and premature death [1]. Endothelial dysfunction is characterized by increased production of vasoconstrictors, such as endothelin and thromboxane A2, and decreased production of vasodilator substances, such as prostacyclin and nitric oxide (NO). Endothelium-derived NO, specifically, is essential for homeostasis of vascular tone by activating guanylate cyclase, leading to increased formation of cGMP and subsequently smooth muscle relaxation [2]. NO is formed in the course of transformation of L-arginine to citrulline, a reaction catalyzed by the enzyme NO synthase (NOS) (Fig. 1) [3]. Moreover, L-arginine is also metabolized by arginase to L-ornithine and urea [4]. 
Fig. 1 Synthesis and metabolism of ADMA through the PRMT-DDAH-ADMA pathway. Methylation of arginine residues occurs through different isoenzymes of PRMT. ADMA is an inhibitor of NOS, leading to decrease NO production. ADMA is mainly metabolized by DDAH to L-citrulline and dimethylamine and partly via urinary excretion. ADMA asymmetric dimethylarginine, $D D A H$ dimethylarginine dimethylaminohydrolase, $E R A$ endothelin receptor antagonists, $E T_{A / \mathrm{B}}$ endothelin receptor $\mathrm{A} / \mathrm{B}$, PDE5i phosphodiesterase type 5 inhibitors, $P R M T$ protein arginine $N$-methyl transferases

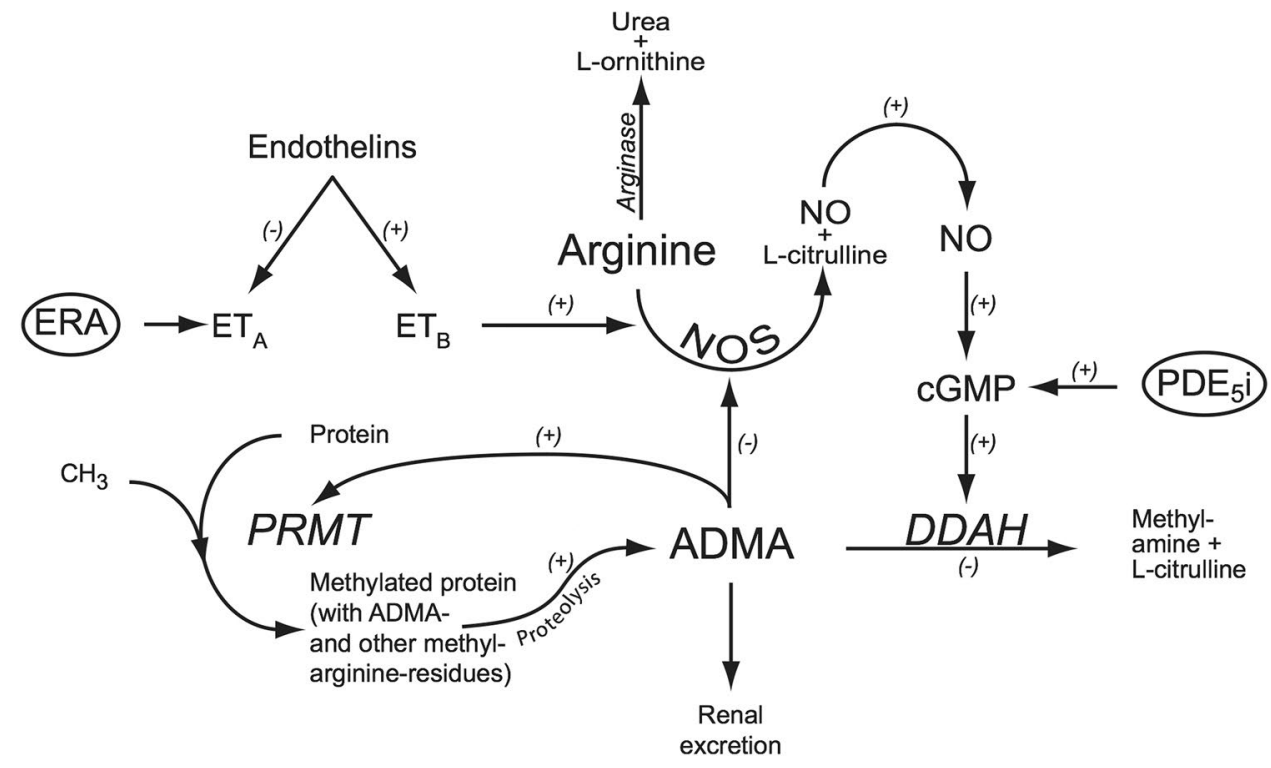

Endogenous analogues of L-arginine that selectively inhibit NOS are involved in the pathogenesis of various cardiovascular diseases [5]. There are three forms of L-arginine residues, asymmetric dimethylarginine (ADMA), symmetric dimethylarginine (SDMA), and mono-methylarginine (L-NMMA), which are formed through methylation by protein arginine $N$-methyltransferases (PRMTs) [6]. Among these, ADMA is the most potent endogenous NOS inhibitor [5]. Elevated ADMA levels can lead to decreased NO production and endothelial dysfunction [7]. Dimethylarginine dimethylaminohydrolase (DDAH) is an important regulator of NO bioavailability and cardiovascular function, by its capacity to metabolize ADMA to L-citrulline and dimethylamine $[8,9]$. Oxidative stress and/or inhibition of DDAH lead to increased ADMA levels in endothelial cells and inhibit NO-mediated endothelium-dependent relaxation of blood vessels [10-12]. The lungs produce a significant amount of ADMA, suggesting that pulmonary dysregulation of ADMA metabolism could be involved in the pathogenesis of PAH [6]. Intracellular ADMA is exported into plasma and exerts negative effects on vascular homeostasis by impairing endothelial function, increasing arterial stiffness and promoting vascular inflammation [13]. Elevated plasma ADMA levels have been reported in several types of pulmonary hypertension $(\mathrm{PH})$ [14-21]. Together, these findings strongly indicate an association between ADMA plasma levels and PAH/PH pathogenesis [22]. As a mediator of endothelial dysfunction and damage, ADMA could serve as a potential biomarker for PAH [18]. ADMA levels may also predict cardiovascular outcome and mortality in PAH [14].

We recently reported that plasma ADMA levels significantly decreased after a single oral dose of the PDE5inhibitor vardenafil in patients with PH [23]. Furthermore, plasma L-arginine concentrations and the L-arginine/ADMA ratio increased over time and were correlated with changes in mean pulmonary artery pressure (mPAP), cardiac output (CO), and cardiac index (CI). The aim of the present study was to investigate baseline plasma ADMA, SDMA, and $\mathrm{L}$-arginine levels in $\mathrm{PAH}$ patients compared to patients with left ventricular systolic dysfunction (LVSD) and healthy subjects.

\section{Method}

\section{Study design and population}

This was an observational and multicenter study. A total of 21 consecutive treatment naïve patients admitted for the first-time diagnostic right heart catheterization (RHC) at the Regional Centers for PAH in Uppsala or Lund between October 2010 and April 2015 were recruited. Inclusion criteria were clinical diagnosis of PAH and age above 18 years. Exclusion criteria were patients in PH group 2-5. Blood samples were taken and examined for the levels of L-arginine, ADMA, SDMA, L-ornithine, and L-citrulline. Detailed medical histories and physical examinations included age, gender, weight, body surface area (BSA), height, electrocardiography, echocardiography, 6 min walking distance (6MWD), NT-proBNP, and RHC. The 6MWD was carried out in accordance with the American Thoracic Society's guidelines [24]. The individuals included were screened for high blood pressure, diabetes mellitus, ischemic heart disease, stroke, renal failure, and thyroid disease. For comparison, 27 healthy subjects without drug treatment and 14 patients treated for LVSD were examined for ADMA, SDMA, and L-arginine. All healthy controls were 
non-smokers and had no symptoms or signs of common cold at the time of recruitment.

The study was approved by the Independent Ethics Committee in Uppsala (Dnr 2010/343) and Lund (Dnr 2010/114, 2011/368, 2011/777), and conducted in accordance with the Helsinki Declaration. All patients gave their informed consent.

\section{Hemodynamic evaluation}

All PAH patients underwent routine RHC as part of the initial diagnostic work-up. RHC was performed at the Hemodynamic Laboratory using a fiberoptic thermodilution pulmonary artery catheter, Becton-Dickinson Criticath SP5 107 HTD catheter at Uppsala University hospital, and a SwanGanz catheter 7.5 F (2.5 mm), Edward Lifesciences LLC, Irvine, CA, USA at Lund University hospital. The catheter was inserted through the right internal jugular vein into the pulmonary artery. Recorded hemodynamic data were: heart rate, central venous pressure (CVP), systolic pulmonary artery pressure (SPAP), mPAP, mean pulmonary artery wedge pressure (mPAWP), mean right atrial pressure (mRAP), CO, and CI. Mixed venous and arterial oxygen saturation was also measured. Pressures were registered with a Siemens ${ }^{\circledR}$ system and flow was calculated with the thermodilution technique or with Fick's principle. Pulmonary vascular resistance (PVR), systemic vascular resistance (SVR), and PVR/SVR were calculated. Systemic blood pressure was measured invasively in Uppsala and non-invasively in Lund. Experienced cardiologists performed all examinations.

\section{Sample preparations and analytical procedures}

Blood samples were obtained from the pulmonary artery or from peripheral veins during diagnostic RHC. All blood samples were collected in EDTA tubes (BD Diagnostics, Burlington, NC, USA) and plasma was retrieved after centrifugation. Plasma was separated and stored at $-70{ }^{\circ} \mathrm{C}$ in Uppsala and at $-80{ }^{\circ} \mathrm{C}$ in Lund waiting for biochemical analysis.

Plasma levels of ADMA, SDMA, L-arginine, L-ornithine, and L-citrulline were analyzed with liquid chromatography-tandem mass spectrometry (LC-MS/MS) at the Swedish National Veterinary Institute in Uppsala, Sweden. Sample pretreatment was as follows. To $100 \mu \mathrm{L}$ of plasma, $50 \mu \mathrm{L}$ of water and $50 \mu \mathrm{L}$ of the internal standard solution containing ${ }^{2} \mathrm{H}_{7}$-ADMA, ${ }^{2} \mathrm{H}_{6}$-SDMA, ${ }^{13} \mathrm{C}_{6}$-arginine, 2H6-ornithine, and ${ }^{2} \mathrm{H}_{7}$-citrulline were added followed by addition of $400 \mu \mathrm{L}$ of acetonitrile/trifluoroacetic acid/propionic acid $(1000 / 0.25 / 10 \mathrm{v} / \mathrm{v} / \mathrm{v})$. The samples were vortexmixed for $5 \mathrm{~min}$ followed by centrifugation for $5 \mathrm{~min}$ at $10,000 \mathrm{~g}$. The supernatants were transferred vials for analysis with ultra-high-performance liquid chromatography-tandem mass spectrometry (UHPLC-MS/MS). A Waters Acquity UPLC system was coupled to a Quattro Ultima Pt tandem quadrupole mass spectrometer with an electrospray interface operating in the positive mode (Waters Corporation, Milford, MA, USA). The column was an Indra Almtakt Amino Acid (length $100 \mathrm{~mm}$, I.D. $2.0 \mathrm{~mm}$, particle size $3 \mu \mathrm{m}$ ) kept at $25{ }^{\circ} \mathrm{C}$. The mobile phase consisted of (A) $100 \mathrm{mM}$ ammonium formate in water and (B) $0.1 \%$ formic acid in acetonitrile. The injection volume was $10 \mu \mathrm{L}$. The elution was carried out as follows: isocratic at $80 \%$ A for $1 \mathrm{~min}$, increase to $95 \%$ A during $1 \mathrm{~min}$, constant at $95 \%$ A for $5.5 \mathrm{~min}$, and decrease to $80 \%$ A during $0.1 \mathrm{~min}$, constant at $80 \%$ A for $2.4 \mathrm{~min}$. The flow-rate was $200 \mu \mathrm{L} / \mathrm{min}$. The five analytes were quantified simultaneously in the same chromatographic run using a positive capillary voltage of $0.50 \mathrm{kV}$ and a cone voltage of $40 \mathrm{~V}$. The desolvation and source block temperatures were 350 and $120^{\circ} \mathrm{C}$, respectively, and the cone and desolvation gas flows were 120 and $924 \mathrm{~L} / \mathrm{h}$, respectively. The quantifications were performed in the selected reaction monitoring (SRM) mode with the collision cell filled with argon gas at a pressure of $1.9 \times 10^{-3} \mathrm{mBar}$. The mass transitions used in SRM were $m / z, 203 \rightarrow 46$ for ADMA (collision energy $18 \mathrm{eV}$ ), $\mathrm{m} / \mathrm{z} 210 \rightarrow 77$ for $\left[{ }^{2} \mathrm{H}_{7}\right]$-ADMA (collision energy $23 \mathrm{eV}$ ), $\mathrm{m} / \mathrm{z}, 203 \rightarrow 172$ for SDMA (collision energy $16 \mathrm{eV}), m / z, 209 \rightarrow 116$ for $\left[{ }^{2} \mathrm{H}_{6}\right]$-SDMA $(19 \mathrm{eV})$, $\mathrm{m} / \mathrm{z} 175 \rightarrow 70$ for arginine (collision energy $18 \mathrm{eV}$ ), $\mathrm{m} / \mathrm{z}$ $181 \rightarrow 74$ for $\left[{ }^{13} \mathrm{C}_{6}\right]$-arginine (collision energy $18 \mathrm{eV}$ ), $\mathrm{m} / \mathrm{z}, 133 \rightarrow 70$ for ornithine (collision energy $13 \mathrm{eV}$ ), $\mathrm{m} / \mathrm{z}$ $139 \rightarrow 76$ for $\left[{ }^{13} \mathrm{H}_{6}\right]$-ornithine (collision energy $14 \mathrm{eV}$ ), $\mathrm{m} / \mathrm{z}$ $176 \rightarrow 113$ for citrulline (collision energy $18 \mathrm{eV}$ ), and $\mathrm{m} / \mathrm{z}$ $183 \rightarrow 120$ for $\left[{ }^{13} \mathrm{C}_{7}\right]$-citrulline (collision energy $16 \mathrm{eV}$ ). The dwell time was $0.010 \mathrm{~s}$. Stock solutions of ADMA, SDMA, arginine, ornithine, citrulline, and the internal standards were prepared in water at approximately $0.1-0.3 \mathrm{mg} /$ $\mathrm{mL}$. The reference standards and the internal standards were obtained from Toronto Research Chemicals (North York, ON, Canada). To check for matrix effects and to compensate for endogenous levels of the analytes in the spiked plasma, calibration samples were constructed for all three analytes in both water and in control plasma. The calibration curves were constructed using the chromatographic peak area ratio (analyte/internal standard) as a function of analyte concentration. The calibration functions were calculated by linear curve fit using a weighting factor of $1 / x^{2}$ for all three analytes. The calibration range for ADMA was 0.090-3.4 $\mu \mathrm{M}$ and the precision was in the range of $5.3-7.3 \%$. The calibration range for SDMA was $0.38-3.0 \mu \mathrm{M}$ and the precision was in the range of $5.8-9.3 \%$. The calibration range for arginine was $4.5-150 \mu \mathrm{M}$ and the precision was in the range of 3.5-6.2\%. The calibration range for ornithine was $4.5-151 \mu \mathrm{M}$ and the precision was in the range of 4.1-5.2\%. The calibration range for citrulline was $4.4-150 \mu \mathrm{M}$ and the precision was in the range of $2.5-4.8 \%$. 


\section{Statistical analysis}

Clinical characteristics, biochemical indicators, and hemodynamic parameters were summarized by median (interquartile range) and investigated biomarkers by median (IQR) or median (range). Non-parametric tests were used due to non-normal data distributions and small sample size. Differences between two groups were evaluated with the Mann-Whitney $U$ test. For testing differences between three groups (patients with PAH, LVSD and healthy subjects), the Kruskal-Wallis test was used. In cases where results of the Kruskal-Wallis test were significant, Mann-Whitney $U$ tests were performed to compare the PAH patients with LVSD patients and healthy subjects, separately. Spearman's test was used to evaluate the association between hemodynamic variables and methylarginines. Multiple linear regression analysis was used to evaluate associations between L-arginine and 6MWD. $p$ values $<0.05$ were considered statistically significant. Statistical analyses were performed with SAS 9.3 (SAS Institute Inc, Cary, NC, USA) and IBM SPSS Statistics package v. 24.

\section{Results}

\section{Demographics, biochemical, and hemodynamic characteristics}

Patient characteristics and biochemical data in patients with PAH and LVSD and in healthy subjects are presented in Table 1. The PAH group consisted of 13 women $(62 \%)$ and eight men (38\%) with a median age of $73(45-85)$ years. Four of these patients had PAH associated with connective tissue disease and 17 had idiopathic PAH. Three of the PAH patients had a history of ischemic heart disease. None of these patients had signs of left-sided heart disease during the study (PAWP $=12,6$ and $8 \mathrm{mmHg}$ ). Patients with $\mathrm{PH}$ due to left heart disease have PAWP $>15 \mathrm{mmHg}$ according to ESC guidelines for the diagnoses and treatment of pulmonary hypertension [1]. Hemodynamic parameters in PAH patients are shown in Table 2. The LVSD group consisted of eight women (57\%) and six men (43\%) with a median age of 67 (48-82) years. The majority of the LVSD patients had dilated cardiomyopathy of non-ischemic orient with a median ejection fraction of 33 (15-35) \%. Based on echocardiography, no right ventricular failure was present in
Table 1 Clinical characteristics of patients with PAH, LVSD, and healthy controls

\begin{tabular}{|c|c|c|c|c|c|c|}
\hline \multirow[t]{2}{*}{ Parameter } & \multicolumn{2}{|c|}{ PAH } & \multicolumn{2}{|c|}{ LVSD } & \multicolumn{2}{|c|}{ Healthy subjects } \\
\hline & $n$ & Median (IQR) & $n$ & Median (IQR) & $n$ & Median (IQR) \\
\hline \multicolumn{7}{|l|}{ Clinical features } \\
\hline Sex (male/female) & 21 & $8 / 13$ & 14 & $6 / 8$ & 27 & $8 / 19$ \\
\hline Age (years) & 21 & $73(40)$ & 14 & $67(19)$ & 27 & $61(30-77)$ \\
\hline Weight $(\mathrm{kg})$ & 21 & $75(37)$ & 13 & $86(27)$ & & N/A \\
\hline $\operatorname{BSA}\left(\mathrm{m}^{2}\right)$ & 21 & $1.8(0.5)$ & 13 & $1.9(0.4)$ & & N/A \\
\hline WHO/NYHA class (II/III/IV) & 21 & $5 / 15 / 1$ & 14 & $8 / 6 / 0$ & & N/A \\
\hline 6MWD (m) & 18 & $245(288)$ & 12 & $415(195)^{*}$ & & N/A \\
\hline Diabetes mellitus (yes/no) & 21 & $5 / 16$ & 14 & $3 / 11$ & 27 & $0 / 27$ \\
\hline Hypertension (yes/no) & 21 & $14 / 7$ & 14 & $7 / 7$ & 27 & $0 / 27$ \\
\hline $\mathrm{AF}$ (yes/no) & 21 & $4 / 17$ & 14 & $2 / 12$ & 27 & $0 / 27$ \\
\hline Ischemic heart disease (yes/no) & 21 & $3 / 18$ & 14 & $1 / 13$ & 27 & $0 / 27$ \\
\hline History of stroke (yes/no) & 21 & $1 / 20$ & 14 & $0 / 14$ & 27 & $0 / 27$ \\
\hline \multicolumn{7}{|l|}{ Drug treatment } \\
\hline Anticoagulants (yes/no) & 21 & $11 / 10$ & 14 & $5 / 9$ & 27 & $0 / 27$ \\
\hline Diuretics (yes/no) & 21 & $15 / 6$ & 14 & $13 / 1$ & 27 & $0 / 27$ \\
\hline Digitalis (yes/no) & 21 & $7 / 14$ & 14 & $3 / 11$ & 27 & $0 / 27$ \\
\hline Oxygen (yes/no) & 21 & $6 / 15$ & 14 & $0 / 14$ & 27 & $0 / 27$ \\
\hline \multicolumn{7}{|l|}{ Biochemical indicators } \\
\hline NT-proBNP (ng/L) & 19 & $2194(2068)$ & 14 & $756(1403)^{*}$ & & N/A \\
\hline$S$-Creatinine $(\mu \mathrm{M} / \mathrm{L})$ & 21 & $98(33)$ & 14 & $97(48)$ & & N/A \\
\hline eGFR (mL/min) & 21 & $65.0(30.3)$ & 14 & $61.2(38.8)$ & & N/A \\
\hline
\end{tabular}

Data are presented as median (interquartile range)

$B S A$ body surface area, WHO World Health Organization, $6 M W D$ six-minute walk distance, $A F$ atrial fibrillation, absolute eGFR estimated glomerular filtration rate (Cockcroft Gault formula)

* $p$ value for comparison between PAH vs. LVSD was based on Mann-Whitney $U$ test $(p<0.05)$ 
Table 2 Hemodynamic parameters of in PAH patients

\begin{tabular}{lcc}
\hline Parameter & $n$ & Median (IQR) \\
\hline SAP $(\mathrm{mmHg})$ & 19 & $133.0(16.0)$ \\
mPAP $(\mathrm{mmHg})$ & 19 & $39.0(19.0)$ \\
mPAWP $(\mathrm{mmHg})$ & 19 & $6.0(6.0)$ \\
mRAP $\left(\mathrm{mmHg}^{-}\right)$ & 19 & $7.0(5.0)$ \\
CO $\left(1 \times \mathrm{min}^{-1}\right)$ & 19 & $4.0(1.8)$ \\
CI $\left(1 \times \mathrm{min}^{-1} \times \mathrm{m}^{-2}\right)$ & 18 & $2.3(0.5)$ \\
PVR $(\mathrm{WU})$ & 18 & $7.7(5.7)$ \\
SVR $(\mathrm{WU})$ & 18 & $21.0(8.7)$ \\
PVR/SVR & 17 & $0.4(0.2)$ \\
PA sat $(\%)$ & 19 & $60.3(9.3)$ \\
Art sat $(\%)$ & 18 & $89.4(5.0)$ \\
\hline
\end{tabular}

Data are presented as median (interquartile range)

$S A P$ systemic arterial pressure, $P A P$ pulmonary artery pressure, $P A W P$ pulmonary artery wedge pressure, $C O$ cardiac output, $C I$ cardiac index, $P V R$ pulmonary vascular resistance, $W U$ wood units, $S V R$ systemic vascular resistance, $P A$ pulmonary artery, sat saturation

the patients with LVSD except in one patient. This patient underwent RHC and had an mPAP of 31, mPAWP of 16, and $\mathrm{CO}$ of 5.8, and was diagnosed with $\mathrm{PH}$ due to left heart disease. The patient is included in the result.

\section{Plasma ADMA, SDMA, and L-arginine concentrations}

The plasma ADMA, SDMA, and L-arginine levels in PAH, LVSD, and healthy subjects are shown in Table 3. In PAH, median ADMA was $0.50(0.34-0.91) \mu \mathrm{M}$, SDMA 0.83 (0.47-2.43) $\mu \mathrm{M}, \mathrm{L}$-arginine 55.1 (30.0-116.0) $\mu \mathrm{M}, \mathrm{L}$-citrulline 23.5 (10.6-45.1) $\mu \mathrm{M}$, L-ornithine 83.2 (33.4-126.7) $\mu \mathrm{M}$, L-arginine/ADMA ratio 102.2 (59.3-230.2), L-arginine/Lornithine ratio 0.72 (0.35-1.36), and L-arginine/(L-ornithine + L-citrulline) ratio (GABR) $0.51(0.28-1.08)$.

In LVSD, median ADMA was $0.56(0.50-0.74) \mu \mathrm{M}$, SDMA $0.74(0.50-1.08) \quad \mu \mathrm{M}, \quad$ L-arginine 81.8 (43.8-113.8) $\mu \mathrm{M}$, and L-arginine/ADMA ratio 140.4 (81.2-214.8). The patient with PH with left heart disease had the lowest L-arginine levels $(43.8 \mu \mathrm{M})$ in the LVSD group (Fig. 2). In healthy subjects, median ADMA was 0.36 (0.23-0.44) $\mu \mathrm{M}$, SDMA $0.42(0.32-0.59) \mu \mathrm{M}, \mathrm{L}$-arginine $85.8(58.2-132.8) \mu \mathrm{M}$, and L-arginine/ADMA ratio 237.8 (176.5-365.7).

ADMA and SDMA levels were significantly higher, and L-arginine levels and L-arginine/ADMA ratio were significantly lower in PAH compared to healthy controls $(p<0.001)$. Furthermore, patients with PAH had significantly lower L-arginine levels than patients with LVSD $(p=0.0012)$ (Fig. 2).

\section{Clinical determinants in relation to ADMA, SDMA, and L-arginine concentrations}

A Spearman's correlation to determine the relationship between the clinical determinants, and L-arginine and dimethylarginines was performed. In $\mathrm{PAH}$, L-arginine correlated positively with 6MWD $\left(r_{\mathrm{s}}=0.58, p=0.006\right)$ (Fig. 3) and correlated inversely with creatinine clearance (eGFR)

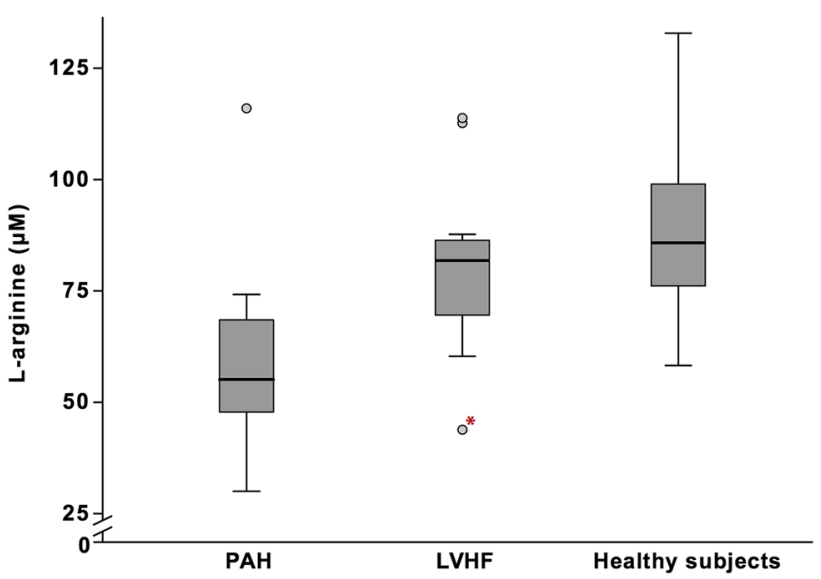

Fig. 2 Plasma L-arginine levels in PAH, LVSD, and healthy subjects. *The marked outlier is the patient with $\mathrm{PH}$ due to left heart disease. There was a statistical significance between PAH vs. LVSD $(p=0.0012)$ and PAH vs. healthy subjects $(p<0.001)$, based on Mann-Whitney $U$ test
Table 3 Plasma ADMA, SDMA, and L-arginine levels in PAH, LVSD, and healthy subjects

\begin{tabular}{|c|c|c|c|c|c|c|}
\hline \multirow[t]{2}{*}{ Parameter } & \multicolumn{2}{|c|}{ PAH } & \multicolumn{2}{|c|}{ LVSD } & \multicolumn{2}{|c|}{ Healthy subjects } \\
\hline & $n$ & median (IQR) & $n$ & median (IQR) & $n$ & median (IQR) \\
\hline ADMA $(\mu \mathrm{M})$ & 21 & $0.50(0.26)$ & 14 & $0.56(0.11)$ & 27 & $0.36(0.09)^{*}$ \\
\hline SDMA $(\mu \mathrm{M})$ & 21 & $0.83(0.31)$ & 14 & $0.74(0.34)$ & 27 & $0.42(0.07)^{*}$ \\
\hline L-Arginine $(\mu \mathrm{M})$ & 21 & $55.1(21.4)$ & 14 & $81.8(18.3)^{*}$ & 27 & $85.8(27.0)^{*}$ \\
\hline L-Arginine/ADMA & 21 & $102.2(52.5)$ & 14 & $140.4(32.2)$ & 27 & $237.8(84.1)^{*}$ \\
\hline
\end{tabular}

Data are presented as median (IQR)

ADMA asymmetric dimethylarginine, SDMA symmetric dimethylarginine

* $p$ value for comparison between PAH vs. LVSD and PAH vs. healthy subjects was based on Mann-Whitney $U$ test $(p<0.05)$ 


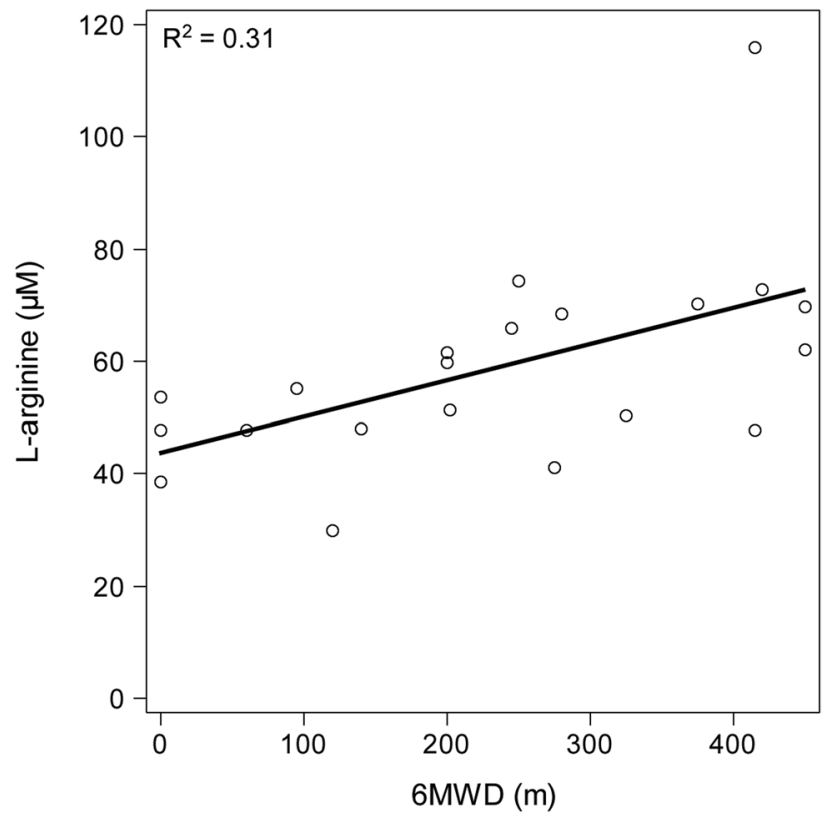

Fig. 3 Association between 6MWD and L-arginine in 21 patients with PAH. Multiple regression analysis was used for statistical analysis

$\left(r_{\mathrm{s}}=-0.52, p=0.015\right)$. L-Arginine/ADMA ratio correlated inversely with WHO functional class $\left(r_{\mathrm{s}}=-0.46, p=0.043\right.$ ) and eGFR $\left(r_{s}=-0.49, p=0.023\right)$. L-Ornithine correlated positively with $6 \mathrm{MWD}\left(r_{\mathrm{s}}=0.54, p=0.012\right)$ and L-citrulline correlated inversely with eGFR $\left(r_{\mathrm{s}}=-0.44, p=0.044\right)$. No significant correlations for cardiovascular risk factors or other clinical determinants were found, and no significant correlations between NT-proBNP and the above clinical determinants in PAH patients were found.

In LVSD, ADMA correlated inversely with 6MWD $\left(r_{\mathrm{s}}=-0.77, p=0.004\right)$. SDMA correlated positively with WHO functional class $\left(r_{\mathrm{s}}=0.54, p=0.048\right)$. L-Arginine and L-arginine/ADMA ratio correlated inversely with eGFR $\left(r_{\mathrm{s}}=-0.69, p=0.010\right)$ and $\left(r_{\mathrm{s}}=-0.56, p=0.046\right)$, respectively. As in $\mathrm{PAH}$ patients, no significant correlations were found between NT-proBNP and clinical determinants were found.

\section{Haemodynamics in relation to ADMA, SDMA, L-arginine, L-citrulline, and L-ornithine concentrations}

A Spearman's correlation to determine the relationship between the hemodynamics and the plasma ADMA, SDMA, and L-arginine levels in $\mathrm{PAH}$ was performed. L-arginine/Lornithine ratio and L-arginine/(ADMA + L-ornithine) ratio correlated inversely with mean aorta pressure $\left(r_{\mathrm{s}}=-0.56\right.$, $p=0.016)$ and $\left(r_{\mathrm{s}}=-0.67, p=0.002\right)$, respectively. No other statistically significant relationships with haemodynamic parameters were seen for the metabolic markers. For
NT-proBNP, there was a positive correlation with sPAP $\left(r_{\mathrm{s}}=0.53, p=0.024\right)$ and PVR/SVR $\left(r_{\mathrm{s}}=0.50, p=0.047\right)$. No other statistically significant relationship for NT-proBNP was seen.

\section{Discussion}

The present study is the first to investigate the plasma levels of L-arginine and dimethylarginines in PAH compared to LVSD. We found that treatment naïve $\mathrm{PAH}$ patients have significantly lower baseline L-arginine levels compared to patients with LVSD on standard medication. In addition, treatment naïve PAH patients have significantly higher plasma ADMA and SDMA and lower plasma L-arginine levels as well as lower L-arginine/ADMA ratios compared to healthy subjects. Furthermore, L-arginine and L-arginine/ ADMA ratio correlated to 6MWD and WHO functional class, respectively, in PAH patients. These results indicate that L-arginine levels may be able to distinguish PAH from LVSD and from healthy subjects.

Decreased L-arginine in PAH patients compared to patients with LVSD is an important finding in the present study. L-Arginine is not exclusively metabolized through NOS to NO and L-citrulline, as it may also be transformed to L-ornithine and urea by arginase [4]. Increased arginase activity leads to lower L-arginine levels and reduces NO production [25]. It is known that PAH patients have higher arginase activity compared to healthy controls, leading to an increased breakdown of L-arginine and thus affects NO synthesis [26]. Furthermore, PAH patients have increased arginase expression in endothelial cells and produce lower levels of NO compared to control cells in vitro [27]. Furthermore, arginase inhibition in a rat model and mice leads to reduced right ventricle systolic pressure and lung tissue remodeling as well as improved NO bioavailability, respectively, representing a potential treatment strategy in $\mathrm{PH}[28$, 29]. We observed significantly decreased plasma L-arginine levels in PAH patients compared to both patients with LVSD and healthy subjects. The explanation to this may be related to the endothelial dysfunction in $\mathrm{PAH}$ in comparison to the heart involvement in LVSD. Therefore, the increased arginase activity in PAH, leading to lower L-arginine levels, could be one explanation to the difference in L-arginine between PAH and LVSD. In addition, the patient with $\mathrm{PH}$ due to left heart disease in the LVSD group had the lowest L-arginine levels. The increased portion of endothelial dysfunction in this patient may explain this. Our findings emphasize the potential value of L-arginine as a clinically relevant specific marker in PAH compared to LVSD. There are other disease states suggesting L-arginine as a potential marker [30, 31]; we believe that L-arginine may be a useful potential marker in many diseases that have impact on the 
NO system. Still, in our study, there was a significant difference in L-arginine between PAH and LVSD and this is an important finding. Furthermore, Beyer et al. showed a strong correlation between plasma L-arginine levels and severity of idiopathic PAH [32]. Currently, there are no known biomarkers to separate PAH to LVSD. Today, NT-proBNP is widely used in routine practice for PAH and LVSD [1]. Although NT-proBNP correlates with myocardial dysfunction and is elevated in all kinds of heart disease, it is not a specific marker for PH. Furthermore, L-arginine/ADMA ratio is considered to be a sensitive marker for atherosclerosis and an indicator of NOS function [33, 34]. In our study, L-arginine/ADMA ratio was decreased in both PAH and LVSD. However, we found a correlation between L-arginine and 6MWD and between the L-arginine/ADMA ratio and WHO functional class in patients with PAH. No correlation between L-arginine and dimethylarginines with 6MWD or NYHA functional class in LVSD was seen. Furthermore, there was no correlation between NT-proBNP and clinical determinants in PAH or LVSD. Today, the diagnostic workup of PAH is time-consuming and expensive. L-Arginine as a potential marker for PAH might simplify this procedure in patients with suspected PAH.

PAH patients had significantly higher plasma levels of ADMA in comparison to healthy controls. Elevated ADMA levels may be the result of reduced renal elimination, inhibition by the metabolizing enzyme DDAH, or increased protein catabolism of PRMT (Fig. 1) [35]. The so-called PRMT-DDAH-ADMA pathway appears to play a crucially regulating role in the nitric oxide production [36]. Furthermore, the elevated ADMA levels enhance the inhibition of eNOS, which may lead to the uncoupling of eNOS, and result in a shift to production of superoxide's instead of NO production [26]. Although not studied in this paper, S-nitrosylation products are also involved in the regulation of the above mentioned enzymes and thus availability of NOS substrates [37]. Plasma ADMA concentration was higher in both patients with PAH and LVSD as compared to healthy subjects in our study. Thus, elevated plasma ADMA levels should be considered a general marker of cardiovascular dysfunction rather than a specific marker of PAH.

Of note, we also found significantly higher plasma SDMA levels in PAH and LVSD patients compared to healthy controls. So far, SDMA has received only limited interest in PAH diagnostics, probably due to lack of evidence for a direct interference of SDMA with NOS activity [38]. However, SDMA may be indirectly involved by competing with $\mathrm{L}$-arginine for the human cationic amino transporter (CAT) hCAT-2B, thereby hampering transport of L-arginine into endothelial cells [5, 7]. Thus, SDMA could indirectly impair NO production by reducing intracellular L-arginine supply [5]. Elevated plasma SDMA levels have been described in patients with IPAH and PAH due to sickle cell disease
$[5,39]$. In an earlier study of the acute effects of vardenafil in PH patients, ADMA and SDMA showed a positive correlation with baseline mRAP, indicating a more severe pulmonary vascular disease [23]. Surprisingly, no correlations between L-arginine, ADMA, SDMA, L-citrulline or L-ornithine, and haemodynamic parameters in patients with PAH were seen in this study. Still, SDMA is more closely correlated with renal function than ADMA $[9,38]$ and is not, as opposed to ADMA, a substrate for DDAH [40]. Actually, SDMA has been considered as an endogenous marker of eGFR [41].

Our study contains several limitations that need to be addressed. The number of patients included was limited, as $\mathrm{PAH}$ is a rare disease making it difficult to recruit a larger number of treatment naïve patients within a reasonable time frame. Furthermore, concomitant diseases and drug treatment for these diseases, such as diabetes mellitus, hypercholesterolemia, and hypertension, might have confounded our findings on L-arginine and other dimethylarginines. Still, this is the first study to compare baseline levels of L-arginine and dimethylarginines between PAH, LVSD and healthy subjects. Further studies in larger materials are warranted to confirm our findings concerning $\mathrm{L}$-arginine as a potential marker for PAH.

\section{Conclusion}

In conclusion, treatment naïve PAH patients had lower L-arginine levels than patients with LVSD. Moreover, L-arginine and the L-arginine/ADMA ratios were lower, while ADMA and SDMA levels were higher in PAH patients compared to healthy subjects. Furthermore, L-arginine correlated with 6MWD and the L-arginine/ADMA ratio correlated to WHO functional class in PAH. Thus, L-arginine may be a useful potential marker for differentiation between PAH and LVSD.

Acknowledgements We would like to thank the patients for their participation. The authors are grateful to Sofia Berg Blomkvist, Karin Kjellström, Frida Ulander (Uppsala University Hospital, Uppsala, Sweden), Karin Paulsson and Anneli Ahlqvist (Skåne University Hospital, Lund, Sweden) for taking blood samples and valuable assistance with monitoring of the study and to Lisa Wernroth (Uppsala Clinical Research Center, Uppsala, Sweden) for statistical analysis. We furthermore acknowledge the support of the staff at the Section for Heart Failure and Valvular Disease at Skåne University Hospital in Lund, Sweden. We also acknowledge the biobank services and retrieval of blood samples performed at Labmedicin Skåne, University and Regional Laboratories, Region Skåne, Sweden.

Financial support was provided by the research and development fund granted by the County Council of Västerbotten, Heart Foundation of Northern Sweden and Swedish Society of Pulmonary Hypertension. These organizations played no role in the data collection, analysis, or interpretation of the data, and have no right in disapproving of the manuscript. 


\section{Compliance with ethical standards}

Conflict of interest A Sandqvist (AS), D. Kylhammar (DK), J. Lundgren (JL), and G. Rådegran (GR) have received unrestricted research grants from the Swedish Society of Pulmonary Hypertension together with Actelion Pharmaceuticals Sweden AB (DK, JL, GR), Bayer Health Care (DK), GlaxoSmithKline AB (AS, GR), and Pfizer AB (DK). DK, JL, GR, and G. Wikström (GW) have received lecture fees from Actelion Pharmaceuticals Sweden AB, Bayer Health Care (GR, GW), GlaxoSmithKline AB (DK, JL, GR, GW), Nordic InfuCare (GR) and Sandoz/Novartis (GR). GR and GW have been investigator in PAH trials for GlaxoSmithKline, Actelion Pharmaceuticals Sweden AB, Pfizer AB, Bayer Health Care and United Therapeutics and in heart transplantation trials for Novartis Sverige AB. GR and GW have been involved in advisory boards for Actelion Pharmaceuticals Sweden AB, Bayer Health Care, Eli Lilly Sweden AB, GlaxoSmithKline AB, and Sanofi AB. The companies have no role in the data collection, analysis, or interpretation, and have no rights to restrict the publishing of the manuscript. The other authors have no competing interest to declare.

Open Access This article is distributed under the terms of the Creative Commons Attribution 4.0 International License (http://creativecommons.org/licenses/by/4.0/), which permits unrestricted use, distribution, and reproduction in any medium, provided you give appropriate credit to the original author(s) and the source, provide a link to the Creative Commons license, and indicate if changes were made.

\section{References}

1. Galiè N, Humbert M, Vachiery JL, Gibbs S, Lang I, Torbicki A, Simonneau G, Peacock A, Vonk Noordegraaf A, Beghetti M, Ghofrani A, Sanchez MAG, Hansmann G, Klepetko W, Lancellotti P, Matucci M, McDonagh T, Pierard LA, Trindade PT, Zompatori M, Hoeper M, Aboyans V, Vaz Carneiro A, Achenbach S, Agewall S, Allanore Y, Asteggiano R, Paolo Badano L, Albert Barberà J, Bouvaist H, Bueno H, Byrne RA, Carerj S, Castro G, Erol C, Falk V, Funck-Brentano C, Gorenflo M, Granton J, Iung B, Kiely DG, Kirchhof P, Kjellstrom B, Landmesser U, Lekakis J, Lionis C, Lip GY, Orfanos SE, Park MH, Piepoli MF, Ponikowski P, Revel MP, Rigau D, Rosenkranz S, Völler H, Luis Zamorano J (2016) 2015 ESC/ERS Guidelines for the diagnosis and treatment of pulmonary hypertension: the joint task force for the diagnosis and treatment of pulmonary hypertension of the European Society of Cardiology (ESC) and the European Respiratory Society (ERS): Endorsed by: Association for European Paediatric and Congenital Cardiology (AEPC), International Society for Heart and Lung Transplantation (ISHLT). Eur Heart J 37(1):67-119

2. Palmer RM, Ferrige AG, Moncada S (1987) Nitric oxide release accounts for the biological activity of endothelium-derived relaxing factor. Nature 327(6122):524-526

3. Vallance P, Leone A, Calver A, Collier J, Moncada S (1992) Accumulation of an endogenous inhibitor of nitric oxide synthesis in chronic renal failure. Lancet 339(8793):572-575

4. Luiking YC, Ten Have GAM, Wolfe RR, Deutz NEP (2012) Arginine de novo and nitric oxide production in disease states. Am J Physiol Endocrinol Metab 303(10):E1177-E1189

5. Pullamsetti S, Kiss L, Ghofrani HA, Voswinckel R, Haredza P, Klepetko W, Aigner C, Fink L, Muyal JP, Weissmann N, Grimminger F, Seeger W, Schermuly RT (2005) Increased levels and reduced catabolism of asymmetric and symmetric dimethylarginines in pulmonary hypertension. FASEB J 19(9):1175-1177
6. Zakrzewicz D, Eickelberg O (2009) From arginine methylation to ADMA: a novel mechanism with therapeutic potential in chronic lung diseases. BMC Pulm Med 9:5

7. Teerlink T, Luo Z, Palm F, Wilcox CS (2009) Cellular ADMA: regulation and action. Pharmacol Res 60(6):448-460

8. Bode-Böger SM, Scalera F, Ignarro LJ (2007) The L-arginine paradox: importance of the L-arginine/asymmetrical dimethylarginine ratio. Pharmacol Ther 114(3):295-306

9. Palm F, Onozato ML, Luo Z, Wilcox CS (2007) Dimethylarginine dimethylaminohydrolase (DDAH): expression, regulation, and function in the cardiovascular and renal systems. Am J Physiol Heart Circ Physiol 293(6):H3227-H3245

10. Leiper JM, Santa Maria J, Chubb A, MacAllister RJ, Charles IG, Whitley GS, Vallance P (1999) Identification of two human dimethylarginine dimethylaminohydrolases with distinct tissue distributions and homology with microbial arginine deiminases. Biochem J 343(Pt 1):209-214

11. Valkonen V-P, Tuomainen T-P, Laaksonen R (2005) DDAH gene and cardiovascular risk. Vasc Med 10(1):S45-S48

12. Blardi P, de Lalla A, Pieragalli D, De Franco V, Meini S, Ceccatelli L, Auteri A (2006) Effect of iloprost on plasma asymmetric dimethylarginine and plasma and platelet serotonin in patients with peripheral arterial occlusive disease. Prostaglandins Other Lipid Mediat 80(3-4):175-182

13. Wadham C, Mangoni AA (2009) Dimethylarginine dimethylaminohydrolase regulation: a novel therapeutic target in cardiovascular disease. Expert Opin Drug Metab Toxicol $5(3): 303-319$

14. Kielstein JT, Bode-Böger SM, Hesse G, Martens-Lobenhoffer J, Takacs A, Fliser D, Hoeper MM (2005) Asymmetrical dimethylarginine in idiopathic pulmonary arterial hypertension. Arterioscler Thromb Vasc Biol 25(7):1414-1418

15. Skoro-Sajer N, Mittermayer F, Panzenboeck A, Bonderman D, Sadushi R, Hitsch R, Jakowitsch J, Klepetko W, Kneussi MP, Wolzt M, Lang IM (2007) Asymmetric dimethylarginine is increased in chronic thromboembolic pulmonary hypertension. Am J Respir Crit Care Med 176(11):1154-1160

16. Landburg PP, Teerlink T, van Beers EJ, Muskiet FAJ, KappersKlunne MC, van Esser JWJ, Mac Gillavry MR, Biemond BJ, Brandjes DPM, Duits AJ, Schnog JJ (2008) Association of asymmetric dimethylarginine with sickle cell disease-related pulmonary hypertension. Haematologica 93(9): 1410-1412

17. Dimitroulas T, Giannakoulas G, Sfetsios T, Karvounis H, Dimitroula H, Koliakos G, Settas L (2008) Asymmetrical dimethylarginine in systemic sclerosis-related pulmonary arterial hypertension. Rheumatol (Oxford) 47(11):1682-1685

18. Sanli C, Oguz D, Olgunturk R, Tunaoglu FS, Kula S, Pasaoglu H, Cevik A (2012) Elevated homocysteine and asymmetric dimethyl arginine levels in pulmonary hypertension associated with congenital heart disease. Pediatr Cardiol 33(8):1323-1331

19. Shao Z, Wang Z, Shrestha K, Thakur A, Borowski AG, Sweet W, Thomas JD, Moravec CS, Hazen SL, Tang WHW (2012) Pulmonary hypertension associated with advanced systolic heart failure: dysregulated arginine metabolism and importance of compensatory dimethylarginine dimethylaminohydrolase-1. J Am Coll Cardiol 59(13):1150-1158

20. Gorenflo M, Zheng C, Werle E, Fiehn W, Ulmer HE (2001) Plasma levels of asymmetrical dimethyl-L-arginine in patients with congenital heart disease and pulmonary hypertension. J Cardiovasc Pharmacol 37(4):489-492

21. Parikh RV, Scherzer R, Nitta EM, Leone A, Hur S, Mistry V, Macgregor JS, Martin JN, Deeks SG, Ganz P, Hsue PY (2014) Increased levels of asymmetric dimethylarginine are associated with pulmonary arterial hypertension in HIV infection. AIDS 28(4):511-519 
22. Zweier JL, Talukder MAH (2011) Targeting dimethylarginine dimethylaminohydrolases in pulmonary arterial hypertension: a new approach to improve vascular dysfunction? Circulation 123(11):1156-1158

23. Henrohn D, Sandqvist A, Egeröd H, Hedeland M, Wernroth L, Bondesson U, Wikström G (2015) Changes in plasma levels of asymmetric dimethylarginine, symmetric dimethylarginine, and arginine after a single dose of vardenafil in patients with pulmonary hypertension. Vasc Pharmacol 73:71-77

24. ATS Committee on Proficiency Standards for Clinical Pulmonary Function Laboratories (2002) ATS statement: guidelines for the six-minute walk test. Am J Respir Crit Care Med 166(1):111-117

25. Pernow J, Jung C (2013) Arginase as a potential target in the treatment of cardiovascular disease: reversal of arginine steal? Cardiovasc Res 98(3):334-343

26. Kao CC, Wedes SH, Hsu JW, Bohren KM, Comhair SAA, Jahoor F, Erzurum SC (2015) Arginine metabolic endotypes in pulmonary arterial hypertension. Pulm Circ 5(1):124-134

27. Xu W, Kaneko FT, Zheng S, Comhair SAA, Janocha AJ, Goggans T, Thunnissen FBJ, Farver C, Hazen SL, Jennings C, Dweik RA, Arroliga AC, Erzurum SC (2004) Increased arginase II and decreased NO synthesis in endothelial cells of patients with pulmonary arterial hypertension. FASEB J 18(14):1746-1748

28. Jung C, Grün K, Betge S, Pernow J, Kelm M, Muessig J, Masyuk M, Kuethe F, Ndongson-Dongmo B, Bauer R, Lauten A, Schulze PC, Berndt A, Franz M (2017) Arginase inhibition reverses monocrotaline-induced pulmonary hypertension. Int J Mol Sci 18(8):E1609

29. Steppan J, Tran HT, Bead VR, Oh YJ, Sikka G, Bivalacqua TJ, Burnett AL, Berkowitz DE, Santhanam L (2016) Arginase inhibition reverses endothelial dysfunction, pulmonary hypertension, and vascular stiffness in transgenic sickle cell mice. Anesth Analg 123(3):652-658

30. Hu L, Gao Y, Cao Y, Zhang Y, Xu M, Wang Y, Jing Y, Guo S, Jing F, Hu X, Zhu Z (2016) Identification of arginine and its "Downstream" molecules as potential markers of breast cancer. IUBMB Life 68(10):817-822

31. Vissers YLJ, Dejong CHC, Luiking YC, Fearon $\mathrm{KCH}$, von Meyenfeldt MF, Deutz NEP (2005) Plasma arginine concentrations are reduced in cancer patients: evidence for arginine deficiency? Am J Clin Nutr 81(5):1142-1146
32. Beyer J, Kolditz M, Ewert R, Rubens C, Opitz C, Schellong S, Hoeffken G, Halank M (2008) L-arginine plasma levels and severity of idiopathic pulmonary arterial hypertension. VASA 37(1):61-67

33. Notsu Y, Yano S, Shibata H, Nagai A, Nabika T (2015) Plasma arginine/ADMA ratio as a sensitive risk marker for atherosclerosis: Shimane CoHRE study. Atherosclerosis 239(1):61-66

34. Celik M, Iyisoy A, Celik T, Yilmaz MI, Yuksel UC, Yaman H (2012) The relationship between L-arginine/ADMA ratio and coronary collateral development in patients with low glomerular filtration rate. Cardiol J 19(1):29-35

35. Rochette L, Lorin J, Zeller M, Guilland J-C, Lorgis L, Cottin Y, Vergely C (2013) Nitric oxide synthase inhibition and oxidative stress in cardiovascular diseases: possible therapeutic targets? Pharmacol Ther 140(3):239-257

36. Pope AJ, Karuppiah K, Cardounel AJ (2009) Role of the PRMTDDAH-ADMA axis in the regulation of endothelial nitric oxide production. Pharmacol Res 60(6):461-465

37. Treuer AV, Gonzalez DR (2015) Nitric oxide synthases, S-nitrosylation and cardiovascular health: from molecular mechanisms to therapeutic opportunities (review). Mol Med Rep 11(3):1555-1565

38. Lüneburg N, von Holten R-A, Töpper RF, Schwedhelm E, Maas R, Böger RH (2012) Symmetric dimethylarginine is a marker of detrimental outcome in the acute phase after ischaemic stroke: role of renal function. Clin Sci 122(3):105-111

39. Kato GJ, Wang Z, Machado RF, Blackwelder WC, Taylor JG, Hazen SL (2009) Endogenous nitric oxide synthase inhibitors in sickle cell disease: abnormal levels and correlations with pulmonary hypertension, desaturation, haemolysis, organ dysfunction and death. Br J Haematol 145(4):506-513

40. Baylis C (2006) Arginine, arginine analogs and nitric oxide production in chronic kidney disease. Nat Clin Pract Nephrol 2(4):209-220

41. Kielstein JT, Veldink H, Martens-Lobenhoffer J, Haller H, Burg M, Lorenzen JM, Lichtinghagen R, Bode-Böger SM, Kliem V (2011) SDMA is an early marker of change in GFR after livingrelated kidney donation. Nephrol Dial Transplant 26(1):324-328 